\title{
Improving the Quality of Health Care for Older Adults
}

RAND RESEARCH AREAS

THE ARTS

CHILD POLICY

CIVIL JUSTICE

EDUCATION

ENERGY AND ENVIRONMENT

HEALTH AND HEALTH CARE

INTERNATIONAL AFFAIRS

NATIONAL SECURITY

POPULATION AND AGING

PUBLIC SAFETY

SCIENCE AND TECHNOLOGY

SUBSTANCE ABUSE

TERRORISM AND

HOMELAND SECURITY

TRANSPORTATION AND

INFRASTRUCTURE

WORKFORCE AND WORKPLACE

This product is part of the RAND Corporation research brief series. RAND research briefs present policy-oriented summaries of published, peer-reviewed documents.

Corporate Headquarters 1776 Main Street P.O. Box 2138

Santa Monica, California 90407-2138

TEL 310.393 .0411

FAX 310.393 .4818

(c) RAND 2008

www.rand.org n 2000, RAND Health researchers released the first set of quality measures specifically developed for the vulnerable elderly - those most likely to die or become severely disabled in the next two years (see Who Are the Vulnerable Elderly? on p. 2). The Assessing Care of Vulnerable Elders (ACOVE) indicators reflect the most comprehensive examination ever conducted of the quality of medical care provided to vulnerable older Americans (see What Does a Quality Indicator Look Like? on p. 2).

As summarized in an earlier Research Highlight (The Quality of Health Care Received by Older Adults), the ACOVE measures, which reflect a combination of clinical evidence and expert opinion, were used to assess the care being provided to elderly people by primary care physicians in several large health care systems nationwide.

In phase 2 of the ACOVE study (ACOVE-2), the researchers used the results of these assessments, and the measures themselves, to evaluate several practical interventions in primary care practices aimed at improving performance of some of the most underperformed health care procedures, as identified in ACOVE-1.

This Research Highlight summarizes results of ACOVE-2 and describes a recent revision of the quality measures, known as ACOVE-3.

\section{Overall Quality of Care for Vulnerable Elders Is Inadequate}

Working with a committee of nationally recognized experts in geriatric care, the ACOVE-1 research team identified 22 conditions-including diseases, syndromes, physiological impairments, and clinical situations - that account for the majority of health care received by older adults. Based on reviews of the medical literature and expert opinion, the RAND team proposed a set of quality-of-care indicators for each condition-recommendations that set a minimum standard for acceptable care. The indicators were evaluated by expert panels and the American

\section{Abstract}

The Assessing Care of Vulnerable Elders (ACOVE) indicators were the first set of health care quality indicators developed specifically for the elderly. Vulnerable elders receive on average only half of recommended care; for conditions that affect primarily the elderly, they receive appropriate care-care indicated by ACOVE-less than one-third of the time. According to ACOVE, patients who received better care are more likely to be alive three years later than those who received poorer care. Interventions based on the ACOVE indicators improved the care physicians provided to vulnerable elders for several selected conditions. In 2007, the ACOVE indicators were updated to include more health conditions and to give greater consideration to the appropriateness of care for patients with advanced dementia or an otherwise poor prognosis.

College of Physicians Task Force on Aging. In all, 236 quality indicators were accepted, covering four stages of the health care process: prevention, diagnosis, treatment, and follow-up.

Some of ACOVE's 22 conditions affect all adults; some affect primarily the elderly. When the researchers applied the indicators to assess the quality of care received by vulnerable elderly who were living on their own, that is, not in nursing facilities, they found that, on average, this group receives about half of the care that is recommended for their conditions. For conditions that affect primarily the elderly, such as impaired mobility (difficulty getting around, which can lead to falls), urinary incontinence, and impaired cognitive function, elders received less than onethird of recommended care.

For example, in two Southern California medical groups, 35 percent of vulnerable elders complained of urinary incontinence (a condition 


\section{Who Are the Vulnerable Elderly?}

The researchers developed and tested a simple questionnaire, the Vulnerable Elders Survey (shown in the table), to identify vulnerable elders. Points are assigned for characteristics such as older age and limitations in daily functioning (two points are assigned for extensive limitations). A score of three or more points defines a vulnerable elder. This questionnaire has been used extensively to identify individuals for targeted interventions and to examine the risk of vulnerability for particular conditions.

\begin{tabular}{|l|l|}
\hline Characteristic & Score \\
\hline Self-rated health: fair or poor & +1 \\
\hline $\begin{array}{l}\text { Limitations in physical functioning (carrying } 10 \\
\text { pounds, grasping, reaching, stooping, walking } \\
\text { one-quarter mile) }\end{array}$ & +1 to +2 \\
\hline $\begin{array}{l}\text { Any functional disability (bathing, shopping, } \\
\text { walking, money management, light } \\
\text { housekeeping) }\end{array}$ & +4 \\
\hline Age $75-84$ & +1 \\
\hline Age 85 and over & +3 \\
\hline
\end{tabular}

that becomes more prevalent with age). But only 13 percent of the patients with symptoms of incontinence were offered treatment.

Chronic pain management was also found to be inadequate for vulnerable elders in the two medical groups. Screening for chronic pain, thorough clinical evaluation of pain complaints, follow-up of patients with a history of osteoarthritis $(\mathrm{OA})$, and counseling about potential toxicities of nonsteroidal anti-inflammatory (NSAID) therapy were all performed less frequently than recommended (see figure).

Quality of care matters. The ACOVE researchers also found that patients who receive better care are more likely to be alive three years later than those who received poorer care.

\section{Proportion of Indicated Pain Care Performed}

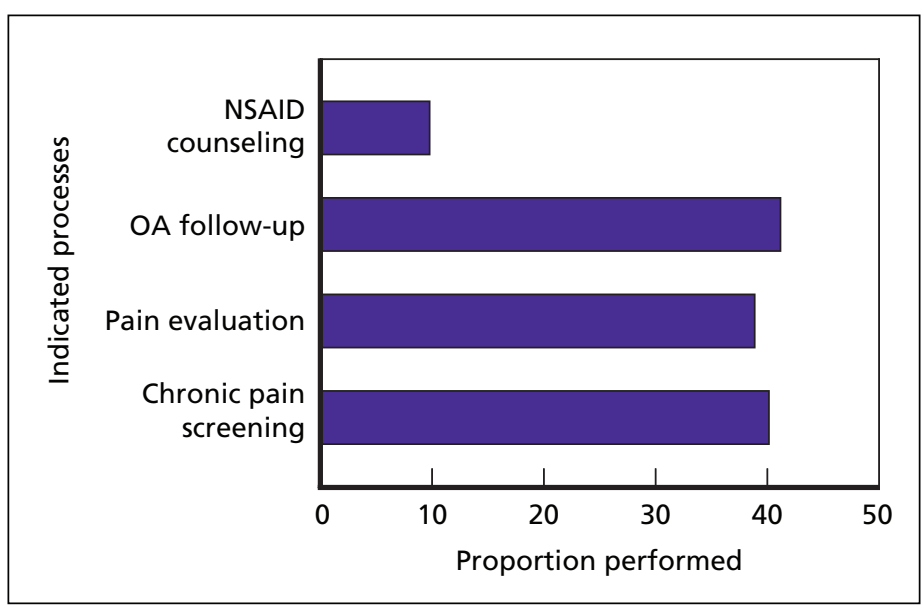

\section{What Does a Quality Indicator Look Like?}

An example of a quality indicator for assessing the reasons for falling:

If a patient reports two or more falls in the past year, or one fall with injury requiring medical care,

Then a "falls evaluation" should be performed, including history and physical exam;

Because some reasons for falling can be treated, which can reduce the risk for future falls.

One might expect that patients with multiple chronic conditions would be the least likely to receive adequate care. But in fact, such patients actually receive care that is better than average. Quality of care was not influenced by age, gender, or degree of "vulnerability."

\section{ACOVE-2 Used the Indicators to Improve Care}

ACOVE-1 showed that vulnerable elderly receive less than one-third of recommended care for conditions associated with aging. The aim of ACOVE-2 was to design simple interventions to improve the care elders receive from their primary care doctors for three conditions associated with aging (falls and mobility impairment, urinary incontinence, and cognitive impairment) and to test the effect of these interventions on care practices in a controlled trial (that is, to compare doctors' offices that implemented the interventions with those that did not). The interventions (which were tailored to each condition) had four components:

- physician education about the condition and the ACOVE-1 indicators

- screening (physical exam and review of patients' history)

- use of medical record prompts (reminders to the doctor or patient to carry out particular health care processes)

- patient education materials combined with efforts to enlist patients' participation in their care.

The interventions were carried out in two large medical groups in Southern California. Office staff were trained to screen patients for the conditions and to implement recommended treatments if the patients had these conditions.

Elderly patients whose doctors' offices implemented the interventions received significantly better care for mobility impairment and incontinence (but not cognitive impairment) than patients whose doctors' offices did not participate. Interestingly, the ACOVE interventions did not stimulate global improvement in the care that patients received - that is, there was no improvement in care for conditions unrelated to the target conditions. However, increased focus on a few conditions did not result in less attention being paid to other conditions. 


\section{Updating the Indicators: ACOVE-3}

To reflect progress in diagnosis and treatment and to create a more comprehensive set of quality measures, the ACOVE team produced a new set of indicators.

A consideration in updating the existing indicators and developing new indicators-especially those pertaining to care processes, such as cancer treatment, that are especially burdensome to the patient-was to determine how to apply the indicators to patients with advanced dementia or an otherwise poor prognosis so as to minimize unnecessary discomfort or potentially futile effort. A panel of clinical experts considered the burden of care involved in each indicator and weighed that burden against the expected outcome of the care-improvement in a patient's condition (e.g., a surgical procedure), prevention of some adverse event (e.g., immunization against the flu), or simply maintaining continuity of care. This process resulted in the exclusion of more than onethird of the indicators for those with advanced dementia and a similar proportion for those with a poor prognosis.

Like the ACOVE-1 indicators, the ACOVE-3 indicators are intended to evaluate whether the care being delivered at the level of the health care system meets minimal standards of quality. What this means is that the indicators are not practice guidelines, which define optimal care; care that does not meet the standards set by the indicators is poor quality care. What it also means is that the indicators are appropriate to assess a health plan or medical group, but not an individual physician, because no one physician is responsible for all the health care a typical elderly patient receives. And like their predecessors, the ACOVE-3 indicators will surely be used to guide the design of future interventions aimed at improving the quality of care that vulnerable elders receive. 


\section{This Highlight summarizes RAND Health research reported in the following publications:}

Chodosh J, Solomon DH, Roth CP, Chang JT, MacLean CH, Ferrell BA, Shekelle PG, Wenger NS. "The Quality of Medical Care Provided to Vulnerable Older Patients with Chronic Pain," Journal of the American Geriatrics Society, Vol. 52, No. 5, May 2004 , pp. $756-761$.

Developing Quality of Care Indicators for the Vulnerable Elderly: The ACOVE Project, Santa Monica, Calif.: RAND Corporation, RB-4545-1, 2004. As of January 2008: www.rand.org/pubs/research_briefs/RB4545-1/

Ganz DA, Wenger NS, Roth CP, Kamberg CJ, Chang JT, MacLean CH, Young RT, Solomon DH, Higashi T, Min L, Reuben DB, Shekelle PG, "The Effect of a Quality Improvement Initiative on the Quality of Other Aspects of Health Care: The Law of Unintended Consequences?" Medical Care, Vol. 45, No. 1, January 2007, pp. 8-18.

Gnanadesigan N, Saliba D, Roth CP, Solomon DH, Chang JT, Schnelle J, Smith R, Shekelle PG, Wenger NS, “The Quality of Care Provided to Vulnerable Older Community-Based Patients with Urinary Incontinence," Journal of the American Medical Directors Association, Vol. 5, No. 3, May-June 2004, pp. 141-146.

Higashi T, Wenger NS, Adams JL, Fung C, Roland M, McGlynn EA, Reeves D, Asch SM, Kerr EA, Shekelle PG, "Relationship Between Number of Medical Conditions and Quality of Care," New England Journal of Medicine, Vol. 356, No. 24, June 14, 2007, pp. 2496-2504.

Min LC, Reuben DB, MacLean CH, Shekelle PG, Solomon DH, Higashi T, Chang JT, Roth CP, Kamberg CJ, Adams J, Young RT, Wenger NS, "Predictors of Overall Quality of Care Provided to Vulnerable Older People," Journal of the American Geriatrics Society, Vol. 53, No. 10, October 2005, pp. 1705-1711.

The Quality of Health Care Received by Older Adults, Santa Monica, Calif.: RAND Corporation, RB-9051, 2004. As of January 2008: www.rand.org/pubs/research_briefs/RB9051/

Reuben DB, Roth C, Kamberg C, Wenger NS, "Restructuring Primary Care Practices to Manage Geriatric Syndromes: The ACOVE-2 Intervention, Journal of the American Geriatrics Society, Vol. 51, No. 12, December 2003, pp. 1787-1793.

Wenger NS, Roth CP, Shekelle PG, the ACOVE Investigators, "Introduction to the Assessing Care of Vulnerable Elders-3 Quality Indicator Measurement Set," Journal of the American Geriatrics Society, Vol. 55, Suppl. 2, October 2007, pp. S247-S252.

Wenger NS, Roth CP, Shekelle PG, Young RT, Solomon DH, Kamberg C, Chang JT, Higashi T, MacLean C, Adams JL, Louie R, Chiang L, Ransohoff K, Hoffing M, Reuben DB, "A Controlled Trial of a Practice-Based Intervention to Improve Primary Care for Falls, Incontinence, and Dementia [abstract], Journal of General Internal Medicine, 2005, Vol. 20, p. 52.

Wenger NS, Solomon DH, Amin A, Besdine RK, Blazer DG, Cohen H, Fulmer T, Ganz PA, Grunwald M, Hall WJ, Katz PR, Kitzman DW, Leipzig RM, Rosenthal RA, ACOVE-3 Clinical Committee, "Application of Assessing Care of Vulnerable Elders-3 Quality Indicators to Patients with Advanced Dementia and Poor Prognosis," Journal of the American Geriatrics Society, Vol. 55, No. s2, October 2007, pp. S457-S463.

Zingmond DS, Wilber KH, MacLean CH, Wenger NS, "Measuring the Quality of Care Provided to Community Dwelling Vulnerable Elders Dually Enrolled in Medicare and Medicaid," Medical Care, Vol. 45, No. 10, October 2007, pp. 931-938.

Abstracts of all RAND Health publications and full text of many research documents can be found on the RAND Health Web site at www.rand.org/health. The RAND Corporation is a nonprofit research organization providing objective analysis and effective solutions that address the challenges facing the public and private sectors around the world. RAND's publications do not necessarily reflect the opinions of its research clients and sponsors. RAND ${ }^{\circledR}$ is a registered trademark. 
THE ARTS

CHILD POLICY

CIVIL JUSTICE

EDUCATION

ENERGY AND ENVIRONMENT

HEALTH AND HEALTH CARE

INTERNATIONAL AFFAIRS

NATIONAL SECURITY

POPULATION AND AGING

PUBLIC SAFETY

SCIENCE AND TECHNOLOGY

SUBSTANCE ABUSE

TERRORISM AND HOMELAND SECURITY

TRANSPORTATION AND INFRASTRUCTURE

WORKFORCE AND WORKPLACE
This PDF document was made available from www.rand.org as a public service of the RAND Corporation.

This product is part of the RAND Corporation research brief series. RAND research briefs present policy-oriented summaries of individual published, peerreviewed documents or of a body of published work.

The RAND Corporation is a nonprofit research organization providing objective analysis and effective solutions that address the challenges facing the public and private sectors around the world.

\section{Support RAND}

$\underline{\text { Browse Books \& Publications }}$

Make a charitable contribution

For More Information

Visit RAND at www.rand.org

Explore RAND Health

View document details
Limited Electronic Distribution Rights

This document and trademark(s) contained herein are protected by law as indicated in a notice appearing later in this work. This electronic representation of RAND intellectual property is provided for noncommercial use only. Unauthorized posting of RAND PDFs to a non-RAND Web site is prohibited. RAND PDFs are protected under copyright law. Permission is required from RAND to reproduce, or reuse in another form, any of our research documents for commercial use. For information on reprint and linking permissions, please see RAND Permissions. 